Elsevier required licence: (C) $<2018>$. This manuscript version is made available under the CC-BY-NC-ND 4.0 license http://creativecommons.org/licenses/bync-nd/4.0/ 


\title{
Meso-scale modelling of steel fibre reinforced concrete with high strength
}

\author{
Xiangwei Liang, Chengqing $\mathrm{Wu}^{*}$ \\ Centre for Built Infrastructure Research, Faculty of Engineering, University of Technology, \\ Sydney, NSW 2007, Australia
}

\begin{abstract}
Based on Delaunay triangulation, a 3D meso-scale model is successfully developed and verified. This approach modelling fibre and concrete separately and linking them with slide line contact has the capability to truly reflect the interfacial behaviour of fibre and mortar, and thus achieve high fidelity of numerical simulations. However, meso-scale modelling usually means tremendous complexity and long computational time. This paper proposes a model to achieve relatively high computation efficiency, as well as accuracy. Besides, the model has the potential to deal with small specimens cut from steel fibre reinforced concrete (SFRC) blocks.
\end{abstract}

Keywords: Meso-scale modelling; Steel fibre; SFRC; Delaunay triangulation

\section{Introduction}

With excellent mechanical properties, steel fibre reinforced concrete (SFRC) has been widely studied experimentally and numerically in recent decades. In these years, with the rapid development of computational technology both in hardware and software, meso-scale modelling has increasingly been an attractive approach for researchers to more deeply and accurately investigate the behaviour of composite materials like SFRC [1]. Instead of a

\footnotetext{
* Corresponding author.

E-mail addresses: xiangwei.liang@student.uts.edu.au (X. Liang), chengqing.wu@uts.edu.au (C. Wu).
} 
homogeneous material usually considered in many numerical studies, concrete is, in fact, a heterogeneous composite consisting of aggregate, cement paste and void. This heterogeneity is even amplified by the addition of fibres. Meso-scale modelling of SFRC is a method that models SFRC components separately, from which some advantages can be expected. For example, the effect of steel fibre with various parameters such as content, aspect ratio and shape can be studied through meso-scale modelling, which can only be done by experiment otherwise. To the best knowledge of the authors, there is no material model specially developed for SFRC in commercial software. Most of the previous and current numerical studies take material models of normal strength concrete (NSC) to model SFRC material by adjusting material parameters according to test results. Nyström and Gylltoft [2] applied the material model developed by Riedel, Hiermayer and Thoma (RHT model) and empirical relations between fracture energy and parameters describing softening curve for SFRCs to conduct a comparative study on the dynamic response of NSCs and SFRCs. Mahmud et al. [3] studied the size effects of ultra-high performance steel fibre reinforced concrete (UHPFRC) beams by modelling UHPFRC as a homogeneous material. $\mathrm{Xu}$ and Wille [4] carried out a study for calibration of the Karagozian \& Case $(\mathrm{K} \& \mathrm{C})$ concrete model in LS-DYNA to obtain more proper parameters for modelling ultra-high performance concrete (UHPC). However, it was far from practical application since the outcomes came only from a single case of UHPC with the compressive strength of $150 \mathrm{MPa}$, and without accounting for variation of steel fibre contents. Meso-scale modelling facilitates selection of material models that are readily there in FEM codes such as ANSYS and LS-DYNA.

The point of meso-scale modelling is to establish appropriate interaction mechanisms between reinforcement and concrete. The behaviour of the interface of reinforcement and cementitious matrix has been studied by a lot of researchers. Shannag et al. [5] conducted tests to inspect 
pullout behaviour of steel fibres from cement-based composites. Soetens et al. [6] and Tuyan and Yazic1 [7] investigated the pull-out behaviour of single hooked-end fibres and found hooked-end fibres have better interfacial bond than smooth or straight fibres. Shi et al. [8] and Ganesan et al. [9] carried out an investigation on bond-slip properties of steel bar and concrete matrix. As reinforcement in concrete, steel fibre has some similar features with the steel bar in terms of reinforcement effect on the concrete matrix, but usually with different damage forms. Upon failure, fibre is usually pulled out from matrix rather than fractured. It was concluded that a complete pull-out process can be divided into three stages: completely bonded state, partially bonded state and completely debonded state [10]. Corresponding to different stages, there are different bond stress distributions on the interface. Aslani and Nejadi [10] observed that the bond characteristics of fibre-matrix depend on several factors, including fibre orientation, embedded fibre length, shape of fibres, and strength of matrix. In numerical simulation, to make concrete and fibre work together appropriately, the rule reflecting this interfacial feature needs to be established. Usually, nodes of fibre can be merged or coupled with concrete. Alternatively, slide line contact can be created between a string of nodes of fibre (called slave nodes) and a string of nodes of concrete (called master nodes), which is represented by the keyword *contact_1D in the hydrocode LS-DYNA. Obviously, slide line contact mode is a more realistic and accurate way than merged nodes or perfect bond since it can mimic fibre pull-out process.

Marfia and Sacco [11] implemented an analysis of crack propagation in cohesive materials with consideration of fibre debonding and pull-out. Oliver et al. [12] proposed a new formulation to model SFRCs and designed a 2D model. $\mathrm{Xu}$ et al. [13] produced a 2D axisymmetric meso-scale model modelling coarse aggregate, cementitious mortar and steel fibre separately to study the effect of aggregate distribution, fibre distribution and fibre 
content on SFRCs under impact loading. The model was able to yield more detailed and realistic internal stress and strain distributions compared with homogeneous models. However, it was limited to 2D and the assumed perfect bond behaviour both between aggregates and mortar and between fibres and mortar is an unrealistic way to represent the interfacial properties. Gal and Kryvoruk [14] conducted a meso-scale analysis of fibre reinforced concrete (FRC) using a two-step homogenization method. Based on the micromechanical model of fibre bridging proposed by Yang et al. [15], Schauffert and Cusatis [16] integrated fibre effect into their previous lattice discrete particle model (LDPM) to develop a new meso-scale model LDPM-F for FRCs, which was also applicable to SFRCs. The LDPM-F model had similar constitutive laws to the microplane model introduced by Bažant and Caner [17, 18] and treatment of fibres to that of Bolander et al. [19]. Nevertheless, this model simulated fibre pull-out phenomena indirectly and it depended on nine material parameters such as bond fracture energy, bond frictional stress and slip hardening-softening parameter, which made it very difficult to collect sufficient experimental data for accurate calibration of these parameters. Besides, it was not specified whether this model had the ability to deal with specimens that are cut from an FRC block. A finite element model with discretely embedded elements was proposed by Cunha et al. [20] to study properties of SFRCs, which considered SFRCs a two-phase material consisting of fibre and concrete. However, a fracture plane had to be predefined making their approach unsuitable for general simulations. Su et al. [21] developed a cylindrical meso-scale model to simulate the dynamic response of ultra-high performance concrete (UHPC) in Split Hopkinson tension tests. UHPC was treated as a two-phase material composed of concrete and fibres. A pull-out test was conducted to obtain parameters for bond slip contact behaviour between concrete and fibres. To avoid the complexity of meshing fibre and concrete conformably, Pros et al. [22] proposed a 2D meso-scale model preluding mesh matching between the two materials using immersed 
boundary method. However, the constitutive model for the fibres in their study has to account for bond slip behaviour between the fibres and the concrete, which depends on angles between the fibre and normal direction of the failure pattern. But it brought about another complexity since the orientation of each fibre has to be worked out. Fang and Zhang [23] developed a 3D meso-scale model for high strength concrete (HSC) reinforced with steel fibres. Delaunay triangulation was adopted by the authors to deal with the meshing of the HSC specimens. Nevertheless, with their Delaunay triangulation strategy, all fibre endpoints have to be contained within the model but not on the surfaces. The shortcoming of their model is that it cannot be used for SFRC specimens prepared by cutting from an SFRC block (see Figure 1Figure 1). As shown in Figure 1Figure 1(a), a piece of SFRC sample for heat tests could be sliced from an SFRC block, and Figure 1Figure 1(b) illustrates that a cylindrical specimen for Split Hopkinson Pressure Bar (SHPB) tests could be drilled out of an SFRC block. Finally in their Delaunay process, initiating a boundary point set may introduce unnecessary points for the Delaunay triangulation, and thus enlarge the already great FE model scale meaninglessly.

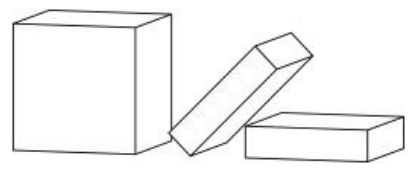

(a) Model for thermal analysis

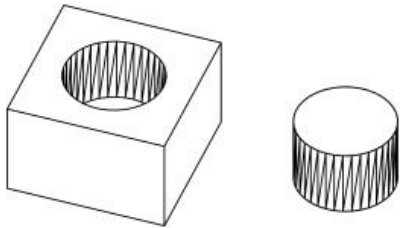

(b) Model for SHPB test simulation

Figure 1. Models cut from SFRC blocks

In this paper, a totally different Delaunay triangulation strategy is adopted so that a more efficient and applicable 3D meso-scale model is developed. This strategy allows points including newly created points to be located right on or close to the boundaries of the model, through which an SFRC model is allowed to be prepared by cutting from an SFRC block. 
Therefore, this model also has the ability to accurately capture the situation that a simulated SFRC sample is cut from an SFRC block, thereby ensuring high fidelity of simulations. This feature is particularly important and necessary when studying very small specimens that are impractical to be fabricated directly and developing small models where random fibres are inappropriate to be created within the models. The meso-scale model is then validated and used to conduct parametric analyses on SFRCs to investigate how steel fibres affect the properties of SFRCs. For comparisons with test results from the literature and computing efficiency, a maximum fibre content of $2 \%$ is chosen in this study. The application of the 'cut' models as shown in Figure 1Figure 1 will be further discussed elsewhere.

\section{Preparation of meso-scale model}

\subsection{Generation of meso-scale geometric model}

In this study, SFRC is considered as a composite consisting of two materials, i.e. steel fibre and mortar, when major concern is the effect of steel fibre on the performance of SFRC. Slide line contact or shared node mode is adopted as interaction mechanism between the fibres and the mortar. To produce a geometric model, fibres are firstly generated randomly within a whole model, and then a model is 'cut' from the whole model.

\subsubsection{Generation of random fibres}

Random fibres are generated in the numerical computing environment MATLAB using function Rand. Dimensions of a model with cuboid shape are defined firstly. Then one endpoint of a fibre is randomly created within the model. The other endpoint of the fibre 
keeping a distance of fibre length is randomly determined if it is contained by the model boundaries. After an intended number of fibres is reached, the fibre generation process is finished. A $100 \mathrm{~mm}$ cube model with $2.5 \%$ volume fraction fibres is shown in Figure 2Figure 2.

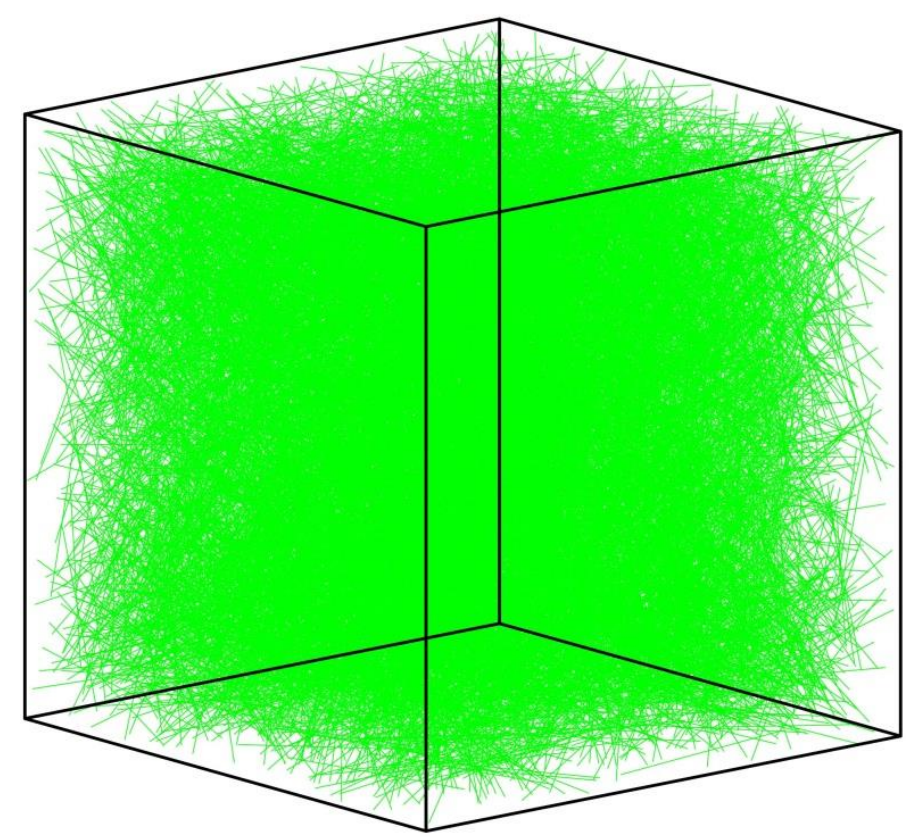

Figure 2. $100 \mathrm{~mm}$ cube model with randomly distributed fibres

\subsubsection{Preparation of geometric model}


The whole model with fibres created in subsection 2.1 is then processed in CAE/CAD

software. An example of a model for the $100 \mathrm{~mm}$ cube model is shown in

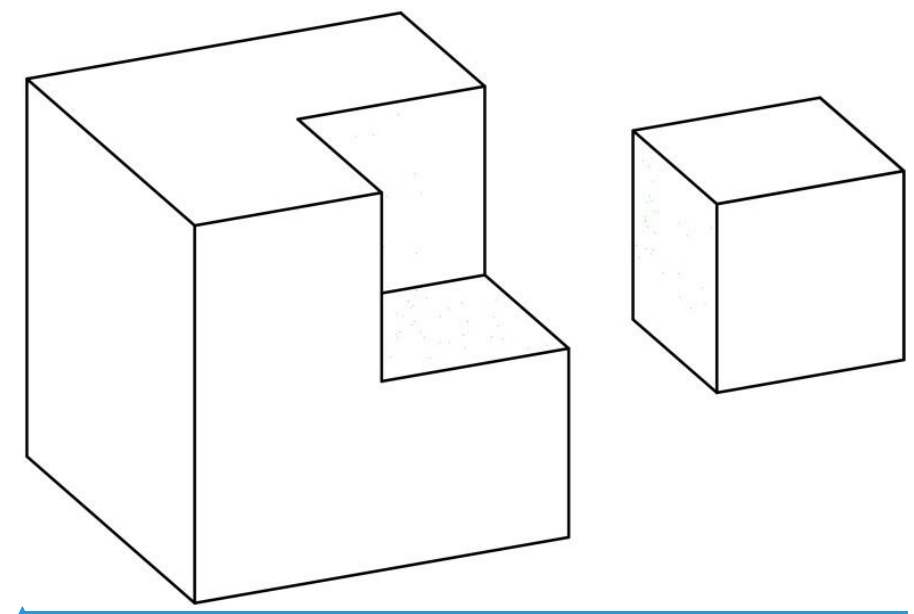

Formatte

Figure 3

Formatte

Figure 3. The model is then encoded into a Delaunay triangulation program in Fortran language and meshed there. It should be noted on rare occasions an existing point in a Delaunay triangulation may be isolated if it is located within a new Delaunay core [24], which in fact means the current inserted point is too close to an existing point. In that case, a fibre with such an endpoint encroaching any existing fibre endpoints will be repositioned to avoid unwanted small element sizes using a parameter that is the minimum height of a newly created tetrahedron. For sake of simplicity, this is explained in a two-dimensional case as shown in Figure 4Figure 4. A newly inserted point $\mathrm{Q}$ close to an existing point $\mathrm{P}$ will form triangles with PQ being one of their edges, which would have too small minimum heights $h_{\min }$ if $\mathrm{Q}$ is too close to $\mathrm{P}$ since $h_{\min }$ is always less than the length of PQ. The encroaching endpoint of the fibre is replaced by a randomly produced point within the model domain while keeping the length of the fibre unchanged. 


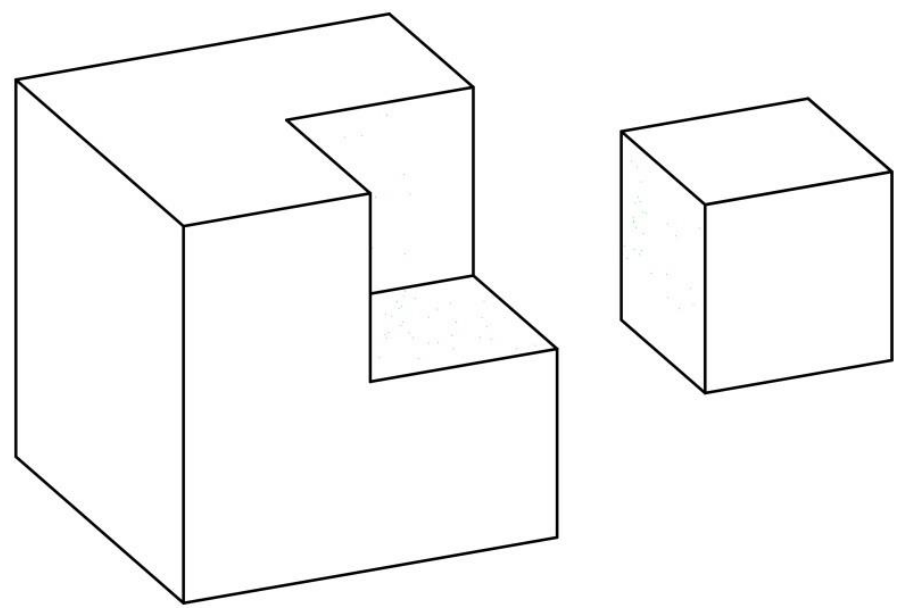

Figure 3. Generation of model

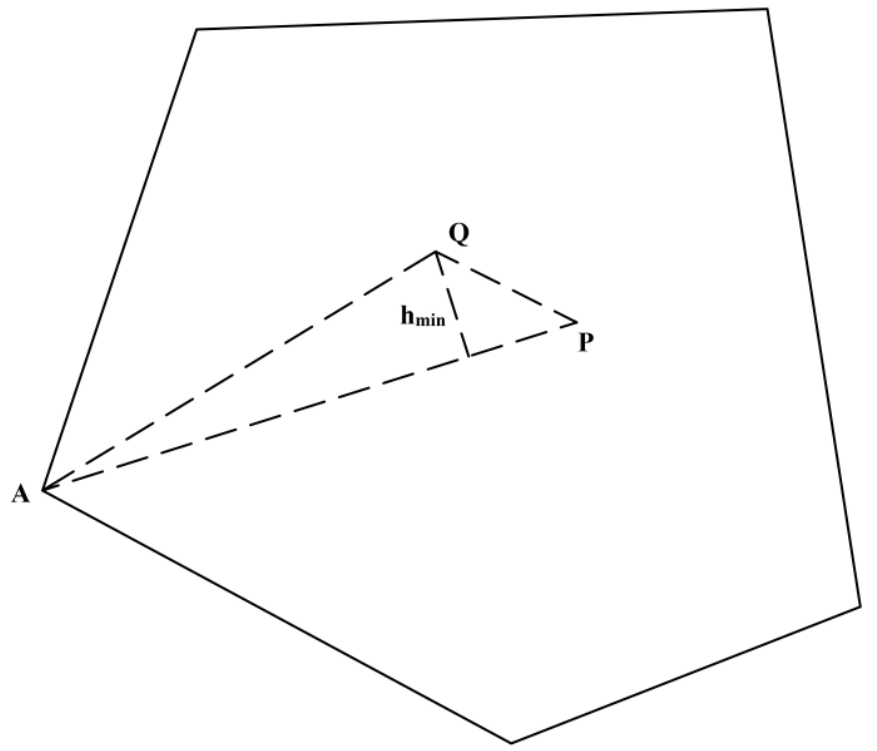

Figure 4. Newly inserted point $\mathrm{Q}$ too close to an existing point $\mathrm{P}$

\subsection{Generation of meso-scale analytical model}

A Delaunay triangulation is a geometric dual of a Voronoi diagram [24-26]. For a given point set on a two-dimensional plane, a Delaunay triangulation of this set ensures the maximum minimum-angle among all possible triangulations. This feature can be extended to n-dimension spaces including 3D space, which makes Delaunay triangulation a desirable tool 
for mesh generation of finite element analysis in case structured mesh is impractical. Incremental algorism of Delaunay triangulation was proposed by Watson [25] and Bowyer [27] in 1981 and has been the most popular Delaunay triangulation method. Sometimes in practice, there is a given point set, segment set and facet set that need to be contained in a Delaunay triangulation, and this kind of triangulation is called Constrained Delaunay triangulation. In this study, for example, the constraining point set (CPS) consists of model vertices, fibre endpoints and fibre divisional points. The model boundaries including the surfaces and the edges are treated as constraining conditions. As shown in Figure 5Figure 5, the six surfaces of the model are contained by the six constraining facets respectively which constitute the initial constraining facet set (CFS) and the 12 edges make up the initial constraining segment set (CSS). Whenever a new point is inserted to the triangulation, it will be checked if any boundaries of the model, i.e. constraining elements, are encroached by the point. As long as all constraining elements exist in the final Delaunay triangulation, the boundaries of the model will be maintained. Figure 5 Figure 5 also shows a containing box that contains all constraining elements and it is used to create the initial Delaunay tetrahedron set (DTeS). 


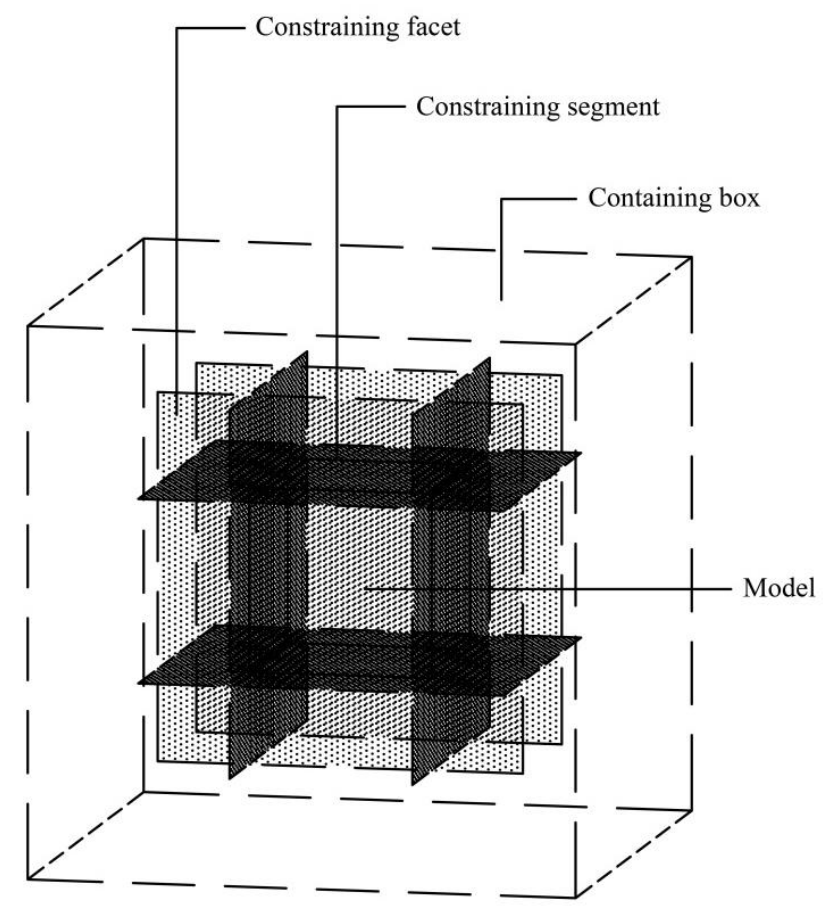

Figure 5. Illustration of constraining facets and segments

Boundary Face Subdivide (BFS) [26] algorism is adopted to process the Delaunay triangulation as the overall guidance and it can be roughly divided into the following steps:

a. Insert each point P in CPS to DTeS one by one, and if any point in CPS lies on a triangle of the Delaunay triangle set of constraining facets (DTS $(\mathrm{CF}))$ then add it to DTS $(\mathrm{CF})$;

b. Segment Subdivide Iterative (SSI) process: check if every segment in the CSS has an empty min-circumsphere. If not, add a divisional point $\mathrm{M}$ in a certain region of its midpoint to CPS, CSS and DTeS. The segment is divided into two new segments and replaced by the latter in CSS. If $M$ lies on any triangle of DTS(CF), add it to DTS(CF);

c. Facet Subdivide Iterative (FSI) process: check if every triangle in DTS(CF) has an empty min-circumsphere. If not, calculate its circumcentre and check if the circumcentre encroaches any segment in CSS. If yes, add a divisional point $M$ in a certain region of the encroached segment to the triangulation, otherwise add the circumcentre. Once a new point is added, the SSI process in step $\mathrm{b}$ needs to be carried out. 
To help understand the above BFS process, a flowchart is shown in Figure 6Figure 6.

To meet the requirement of FE analysis, an optimisation process is needed after the above Delaunay triangulation. Poor quality tetrahedra, such as spear, spike and sliver tetrahedra, have to be removed from DTeS. Herein a combination of two criteria, radius-edge ratio and min-dihedral-angle, are introduced to eliminate poor quality tetrahedra. Radius-edge ratio is a ratio of circumradius to min-edge of a tetrahedron, and min-dihedral-angle is the minimum dihedral angle of six dihedral angles of a tetrahedron. $\mathrm{Li}$ [28] proposed an optimisation strategy to ensure boundaries not to be encroached by adding extra points and it is adopted in this study. As an example to be seen clearly, a Delaunay triangulation of a model with only five fibres is shown in Figure 7Figure 7. It can be seen the developed Delaunay triangulation program has such ability that mesh becomes denser where fibres present. It should be noted for mesh with Delaunay triangulation, one point tetrahedron is used for element formulation of concrete in this study.

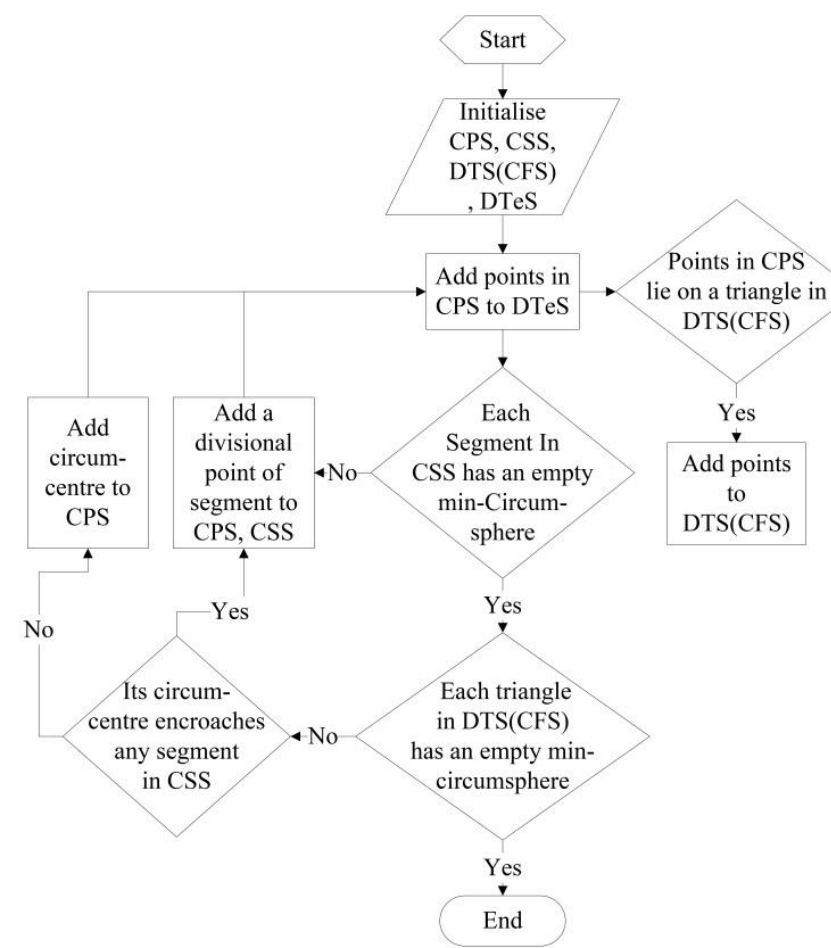


Figure 6. Flowchart of BFS process

\section{Model validation}

\subsection{Material model, contact algorism and material properties}

The hydrocode LS-DYNA is a simulation software package capable of dealing with both dynamic and static problems and is applied to all the calculations in this study. The $\mathrm{K} \& \mathrm{C}$ model in LS-DYNA can properly model key concrete behaviours such as post-peak softening, shear dilation and strain rate [29, 30]. Most importantly, this model can capture implicit confinement of reinforcement which is essential to represent fibre effect on SFRC, and thus is adopted for mortar in this research. For steel fibre, the Mat_Plastic_Kinematic material model is used. This model has the ability to simulate isotropic and kinematic hardening plasticity with the option of including rate effects. It is a very cost-effective model and is available for beam (including truss), shell, and solid elements [31]. Other materials such as plywood used in splitting tension simulation will be discussed in the related subsections. 


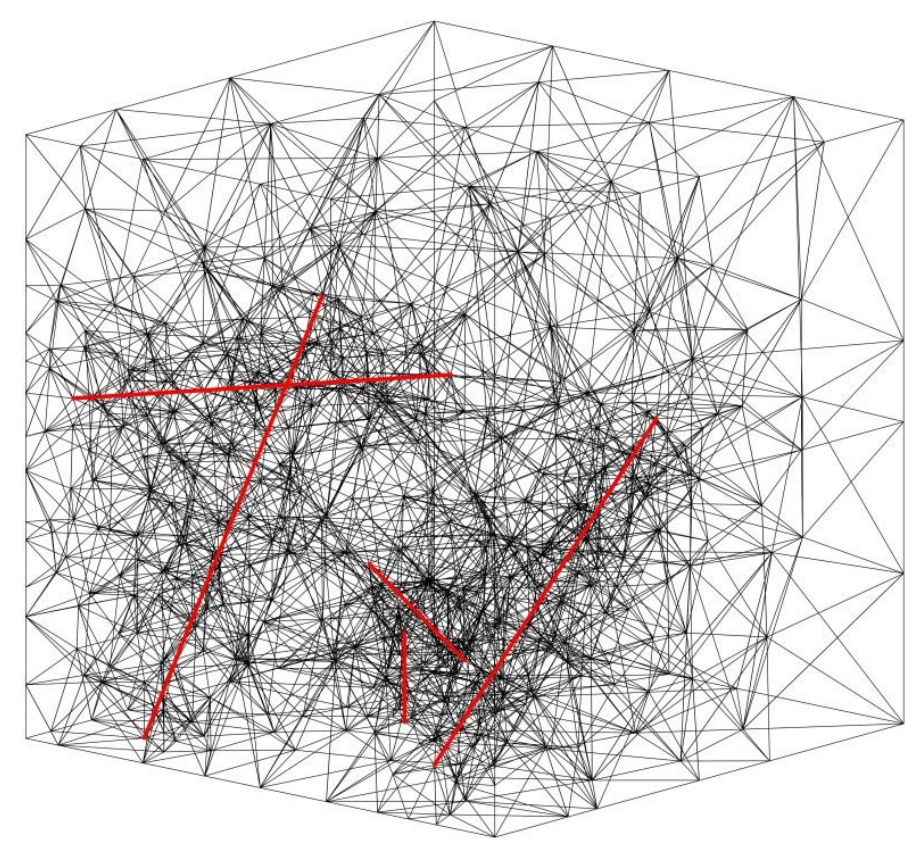

Figure 7. Simple example of Delaunay triangulation of SFRC model

Slide line contact or the keyword * contact_1D in LS-DYNA is chosen for contact algorism between fibres and concrete. This algorism allows a string of fibre nodes (or slave nodes) slide along a string of mortar nodes (or master nodes). In this study fibre nodes and mortar nodes coincide with each other at every fibre node location. As mentioned above, fibre pull-out process can be divided into three different stages, i.e. complete bond, partial bond and complete debond. The contact algorism in LS-DYNA can be expressed as the relationship between bond shear stress and slip as shown in Figure 8Figure 8 where there are two portions. It needs to be noted complete bond and partial bond stages are simplified as the linear portion of the curve in Figure 8Figure 8 while the softening portion corresponds to the stage in which fibre and concrete are completely debonded, and interfacial force is provided purely by friction. At time $\mathrm{n}+1$, the shear force on the interface can be given as follows: 
$f_{n+1}=\min \left(f_{n}-G B \cdot A_{s} \cdot \Delta u, G B \cdot A_{s} \cdot \Delta u_{\max }\right)$

$u_{\max }=S_{\max } \cdot e^{-E X P \cdot D}$

where $G B$ is the bond shear modulus; $A_{s}$ is the bond area of per unit length and $A_{s}=2 \pi R_{e}$; $R_{e}$ is the outer radius of fibre; $u$ is slip strain per unit length; $u_{\max }$ is the maximum slip strain; $S_{\max }$ is the maximum elastic slip strain; EXP is the exponent in damage curve; $D$ is the damage parameter and is given as:

$D_{n+1}=D_{n}+\Delta u$

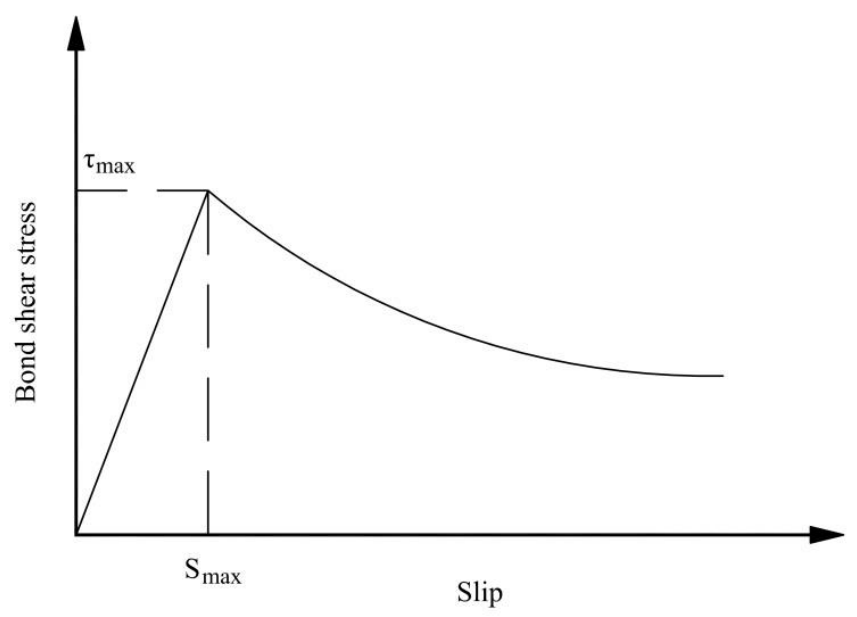

Figure 8 . Bond shear stress versus slip

Properties of steel fibres used in this paper are listed in Table 1Table 1. For subsections 3.2, 3.3, 3.4, 4.1.1 and 4.2.1, the ingredients of the SFRC with high strength are shown in Table 2Table $z$. To define the contact between fibres and mortar, three parameters need to be determined, i.e. $G B, S_{\max }, E X P$ and they are listed in Table 3 Table 3 for contact used in subsections 3.2 to 3.4 . For subsection 3.5, properties of concrete and contact between fibre and concrete are reported 
in that subsection. It is worth noting that though in the current physical models all fibres are straight, some other types of fibres with different fibre shapes can still be properly modelled by using appropriate contact parameters. Prior to the determination, various lengths of fibre element were attempted to obtain a converged result. In this study, the average fibre element length is set at around $1.5 \mathrm{~mm}$ for models with tetrahedral elements and $2 \mathrm{~mm}$ for models with hexahedral elements. It is a requirement for the bond-slip contact algorism in LS-DYNA that there should be at least three nodes in a single contact node set, e.g. a string of nodes for a fibre. In this study fibres with length less than $3 \mathrm{~mm}$ are deleted because too short fibres could result in computing difficulty and they only account for less than $1 \%$ (in most cases $0.5 \%$ ) of the total fibres.

Table 1

Properties of steel fibre

\begin{tabular}{lllll}
\hline Diameter & Density & Modulus of & Poisson's & Yield Stress \\
$(\mathrm{mm})$ & $\left(\mathrm{kg} / \mathrm{m}^{3}\right)$ & Elasticity $(\mathrm{MPa})$ & Ratio & $(\mathrm{MPa})$ \\
\hline 0.9 & 7,800 & $2.1 \times 10^{5}$ & 0.28 & 1,480 \\
\hline
\end{tabular}

Table 2

Constituents of SFRC

\begin{tabular}{ll}
\hline Ingredients & Weight $\left(\mathrm{kg} / \mathrm{m}^{3}\right)$ \\
\hline 42.5 SR Cement & 750 \\
River sand & 1,030 \\
Silica fume & 225 \\
Silica flour & 190 \\
Superplasticizer & 16 \\
Water & 190 \\
Water/Binder & $16.3 \%$ \\
Nano $\mathrm{Al}_{2} \mathrm{O}_{3}$ & 21.7 \\
$1 \% \mathrm{TF}$ & 79 \\
$2 \% \mathrm{TF}$ & 158 \\
\hline
\end{tabular}


Table 3

Parameters of bond-slip contact

\begin{tabular}{lll}
\hline$G B(\mathrm{GPa})$ & $S_{\max }$ & $E X P$ \\
\hline 2.4 & $3 \times 10^{-3}$ & 0.2 \\
\hline
\end{tabular}

\subsection{Single fibre pull-out}

The analytical model shown in Figure 9Figure 9 has a mortar base with a dimension of $20 \times 20 \times 30 \mathrm{~mm}$, and the fibre has a total length of $24 \mathrm{~mm}$ with $20 \mathrm{~mm}$ embedded in the base. Both the mortar and the fibre have an element size of $2 \mathrm{~mm}$ and totally there are 1,500 solid elements for the mortar and 12 beam elements for the fibre. Fibre properties, SFRC ingredients and parameters of bond-slip contact are listed in Table 1Table 1, Table 2Table 2 and Table 3 Table 3 respectively. The curve of pull-out force versus slip is depicted in Figure 10Figure 10 against the test result from [7]. It can be seen the linear portions of the simulation and the test result agree with each other well, while the softening portion of the simulation shows some difference with the test result. This is because the contact algorism adopted in LS-DYNA assumes an exponential curve for the softening portion while the test result is not so. This means reasonable accuracy can be achieved using the bond-slip contact algorism before cracks within the matrix form and spread but some error can occur afterwards. From Figure 10Figure 10, it can be seen the simulation shows similar pull-out work to the test. 


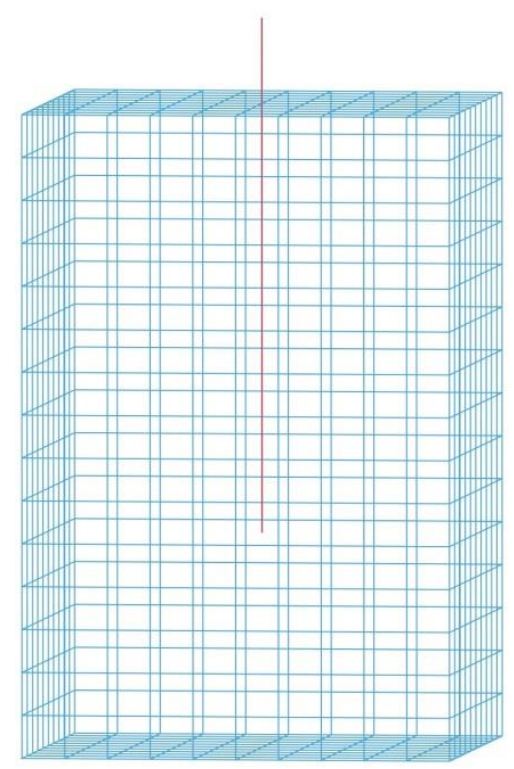

Figure 9. Simulation of single fibre pull-out

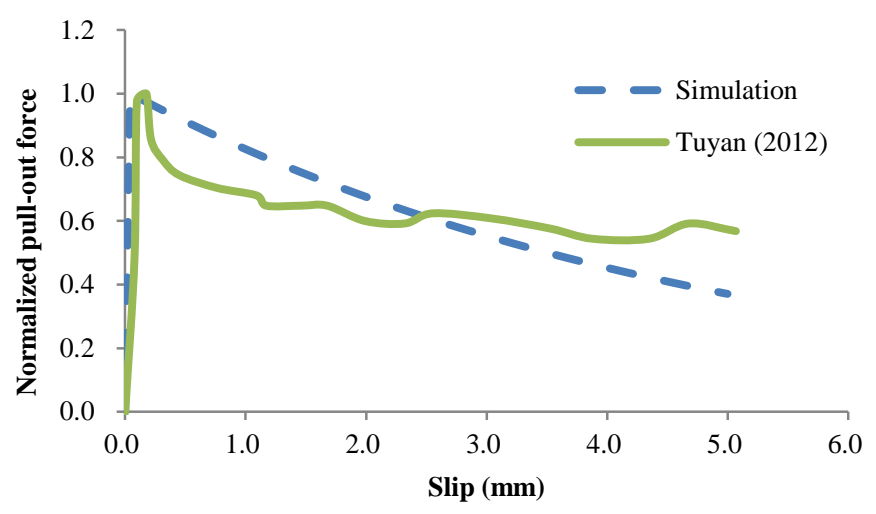

Figure 10. Pull-out force versus slip

\subsection{Quasi-static uniaxial compression}

Totally three models with different fibre dosage, i.e., $0.0 \%, 1.0 \%, 2.0 \%$ by volume respectively, are simulated and results are compared with tests. The model is a $100 \mathrm{~mm}$ cube under uniaxial compression. The analytical model of the sample with $1.0 \%$ fibre volume fraction is displayed in Figure 11Figure 11. There are 97 and 184 fibres in the models with $1.0 \%$ and $2.0 \%$ fibres by volume respectively. The loading steel plate is $60 \mathrm{~mm}$ in length, $60 \mathrm{~mm}$ in width and $30 \mathrm{~mm}$ in height. Elastic material model is applied to the steel plate with solid element type. It has a 
density of $7,830 \mathrm{~kg} / \mathrm{m}^{3}$, modulus of elasticity of $2.07 \times 10^{5} \mathrm{MPa}$ and Poisson's ratio of 0.3 . The model with $2.0 \%$ fibres by volume has 50,541 mortar solid elements and 3,510 fibre truss elements. An automatic surface to surface contact is considered between the loading steel and the concrete.

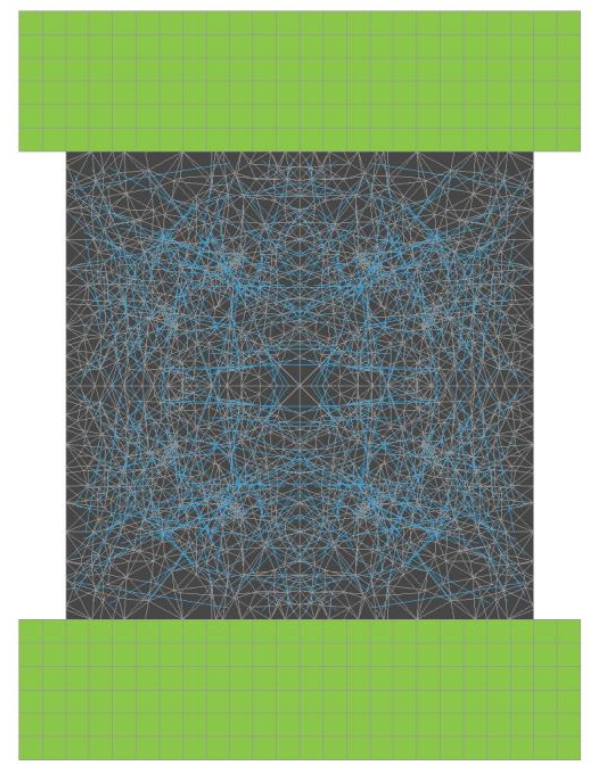

Figure 11. Analytical model of $1.0 \%$ fibre SFRC

Uniaxial compressive tests were conducted so that comparison can be made and reliability of the model can be checked. Ingredients of the mortar mixture are shown in Table 2Table 2, where TF denotes twisted fibre with a diameter of $0.4 \mathrm{~mm}$ and length of $35 \mathrm{~mm}$ and its other properties are listed in Table 1 Table 1 . Properties of bond-slip contact between fibres and cement paste are shown in Table 3Table 3. To prepare the samples, type SR Sulphate Resisting cement was adopted, and small aggregates were made up of river sand with size ranging from $0.16 \mathrm{~mm}$ to $2.5 \mathrm{~mm}$. To achieve high performance, silica materials and Nano- $\mathrm{Al}_{2} \mathrm{O}_{3}$ particles are also added to the mixture.

Curves of compressive stress versus strain from both the tests and the numerical simulations 
are shown in Figure 12Figure 12, and it can be seen the simulation results agree well with the test results. Both the simulation and tests indicate with higher fibre contents, the ultimate compressive strength of SFRC increases so does the corresponding strain, which means the improvement of ductility and toughness.

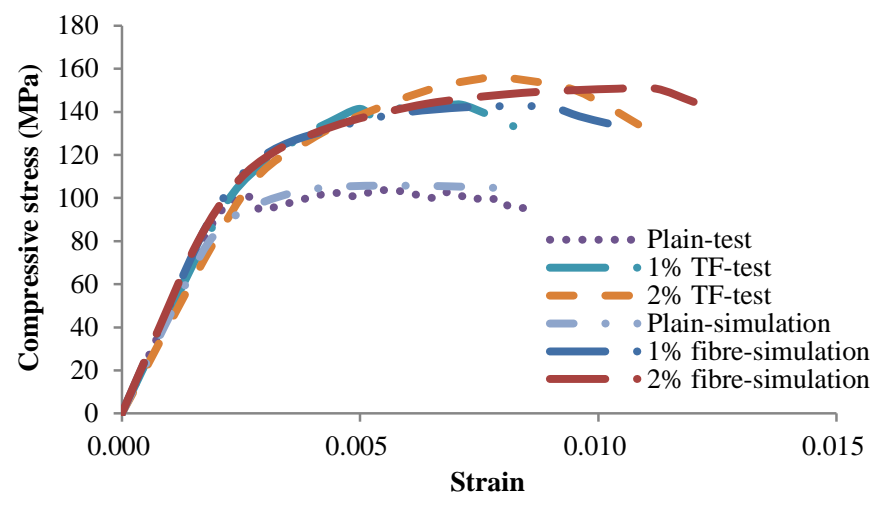

Figure 12. Compressive stress versus strain

\subsection{Flexural tension simulation}

A typical test setup conforming to Chinese national standards GB/T 50081-2002 is shown in Figure 13Figure 13. The full SFRC model is a $100 \times 100 \times 400 \mathrm{~mm}$ prism, but only a $50 \times 100 \times 200 \mathrm{~mm}$ prism for concrete with fibres or a $50 \times 100 \times 400 \mathrm{~mm}$ prism for plain concrete is modelled. The distance between the two supporting rollers is $300 \mathrm{~mm}$, and that between the two loading rollers is $100 \mathrm{~mm}$. Reinforced with $1 \%$ volume fraction steel fibres means there are totally 1,572 fibres within the model. Fibre properties, SFRC ingredients and parameters of bond-slip contact are listed in Table 1Table 1, Table 2Table 2 and Table 3Table 3 respectively. Both the steel loading plate and the steel rollers have the identical properties with the steel plate used in subsection 3.3. However, the loading plate is treated as a rigid material while the elastic material model is applied to the rollers. The FEA model with fibres is displayed in Figure 14Figure 14. There are totally 133,637 tetrahedral elements for the 
concrete matrix, 7,892 truss elements for the fibres, 2,808 solid elements for the rollers and 300 solid elements for the loading plate. For the plain concrete model, an element size of $5 \mathrm{~mm}$ is applied to the concrete. Automatic surface to surface contact is considered between the loading plate and the steel rollers and between the steel rollers and the concrete.

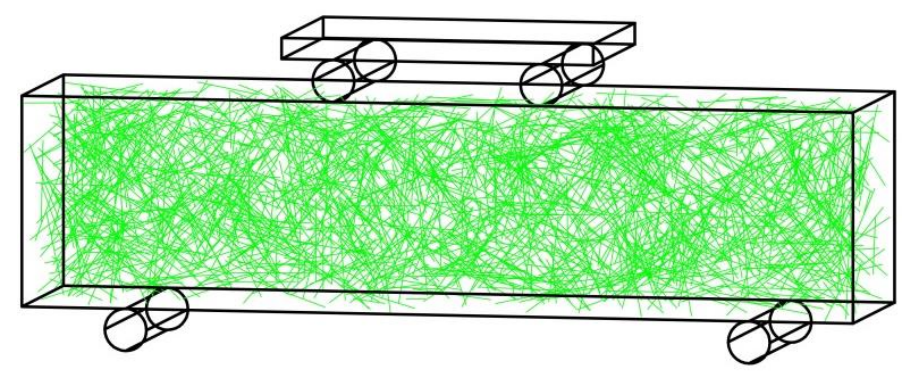

Figure 13. Geometric model for flexural tension simulation

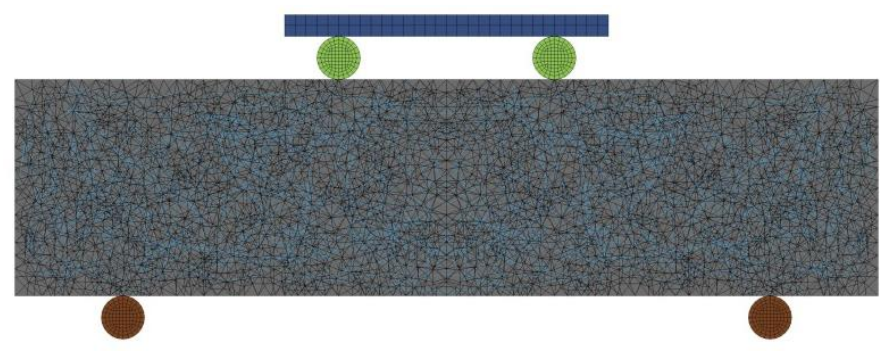

Figure 14. Analytical model for flexural tension simulation

Comparison between numerical simulation and test results is shown in Figure 15Figure 15, where TF denotes twisted fibre. It can be seen the simulation well predicts the peak load and the ductility of SFRC reinforced with $1 \%$ fibres by volume. By contrast, the plain specimen shows very brittle behaviour, as well as low peak load at only $35 \mathrm{kN}$. 


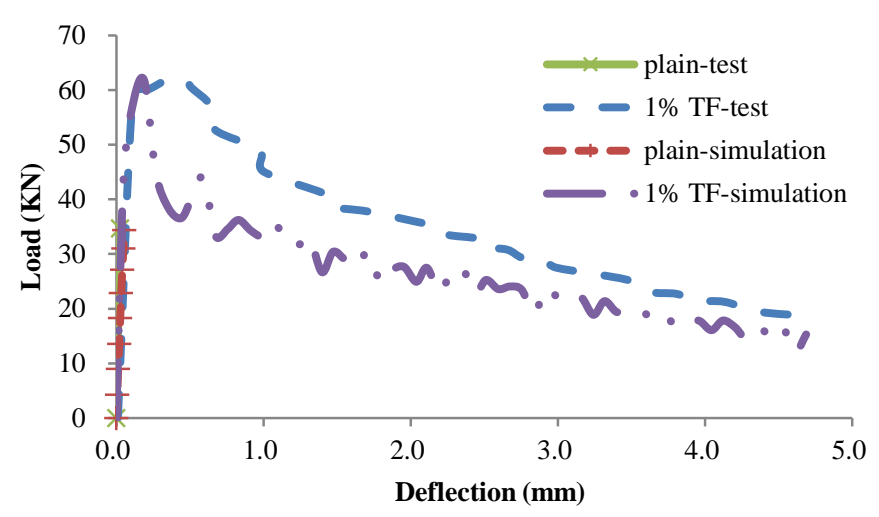

Figure 15. Load versus mid-span deflection

\subsection{Splitting tension simulation}

In this subsection, a model of a $150 \mathrm{~mm}$ SFRC cube reinforced with $1 \%$ steel fibres by volume is prepared and analysed, and numerical results are compared with test results from $[32,33]$. Within the full model, there are totally 1,326 fibres with a diameter of $0.9 \mathrm{~mm}$ and a length of $40 \mathrm{~mm}$. The geometric model is displayed in Figure,16Figure 16. The loading setup shown in Figure 16Figure 16 complies with Chinese national standards GB/T 50081-2002. Two arc-shaped steel plates with the same depth as the model are symmetrically placed on the bottom and top of the model cushioned by two pieces of plywood. Properties of the steel plate are the same as used for uniaxial compression in subsection 3.3. Plastic kinematic material model is adopted for the plywood and its properties are listed in Table 4Table 4. The concrete matrix has a compressive strength of $60 \mathrm{MPa}$. The fibres are assumed to have the same properties as listed in Table 1Table 1. For the slide line contact, the three parameters $G B, S_{\max }$ and EXP are listed in Table 5Table 5. Material model and element type for concrete and fibre remain the same as in the previous subsection. 


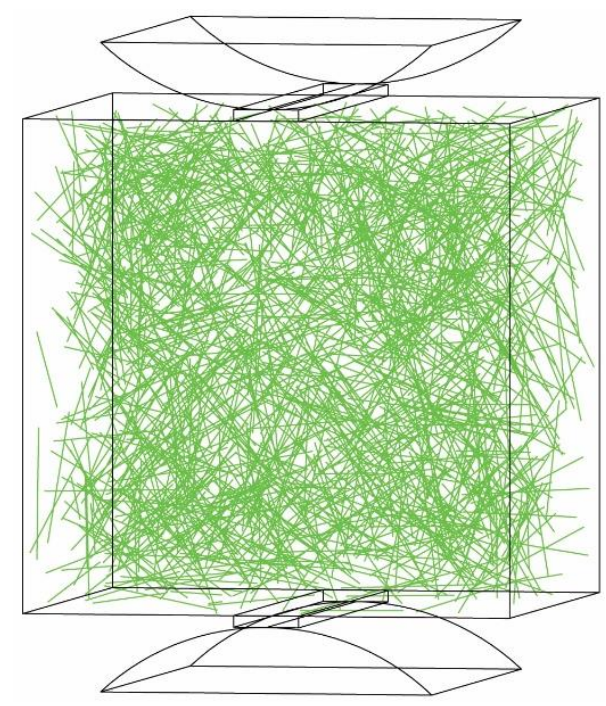

Figure 16. Geometric model for splitting tension simulation

Table 4

Properties of plywood

\begin{tabular}{lllll}
\hline $\begin{array}{l}\text { Density } \\
\left(\mathrm{kg} / \mathrm{m}^{3}\right)\end{array}$ & $\begin{array}{l}\text { Modulus of } \\
\text { Elasticity }(\mathrm{MPa})\end{array}$ & $\begin{array}{l}\text { Tangent modulus } \\
(\mathrm{MPa})\end{array}$ & $\begin{array}{l}\text { Poisson's } \\
\text { Ratio }\end{array}$ & $\begin{array}{l}\text { Yield Stress } \\
(\mathrm{MPa})\end{array}$ \\
\hline 600 & 6,000 & 1,000 & 0.3 & 30 \\
\hline
\end{tabular}

Table 5

Parameters of bond-slip contact for splitting tension

\begin{tabular}{lll}
\hline$G B(\mathrm{GPa})$ & $S_{\max }$ & $E X P$ \\
\hline 1.8 & $3 \times 10^{-3}$ & 0.2 \\
\hline
\end{tabular}

The analytical model shown in Figure 17 Figure 17 has 99,597 tetrahedral elements for the concrete, 5,337 truss elements for the fibres, 760 solid elements for the plywood and 1,900 solid elements for the loading steel plate. It should be noted only the middle part of the loading steel is modelled for simplification purpose and this doesn't incur any difference for the simulation result since a rigid material model is used for the loading steel. Automatic surface to surface contact is considered between the loading steel and the plywood and between the plywood and the concrete. 


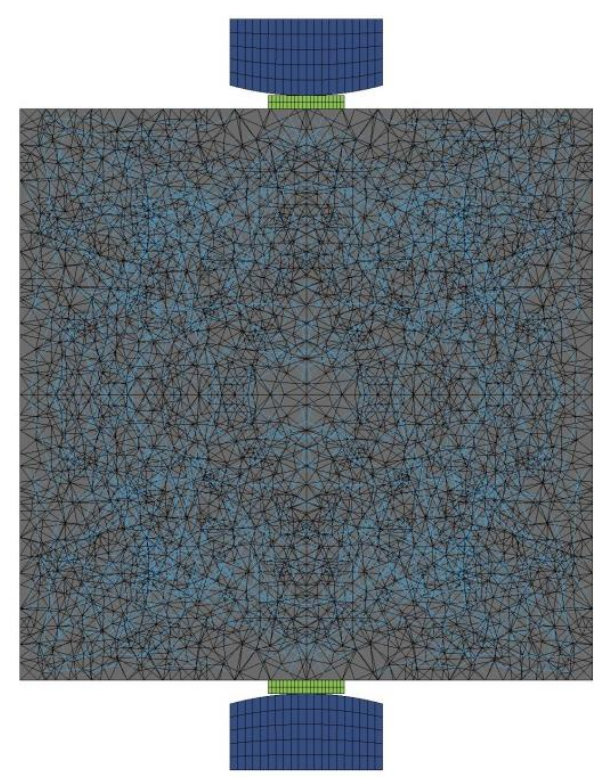

Figure 17. Analytical model for splitting tension simulation

Simulation results and test results are shown in Figure 18Figure 18. It can be seen for both plain concrete and fibre reinforced concrete, the simulation results agree quite well with the test results. The curves show with the addition of $1 \%$ volume fraction steel fibres concrete displays higher strength and much better ductility than its plain counterpart. For plain concrete, the ultimate stress is $4.62 \mathrm{MPa}$ calculated from simulation and $4.53 \mathrm{MPa}$ obtained by experiment, while deformation is smaller than $0.1 \mathrm{~mm}$. For concrete with $1 \%$ steel fibre by volume, the ultimate stress is 6.22 MPa calculated from simulation and 6.04 MPa obtained by experiment, while deformation is larger than $1 \mathrm{~mm}$.

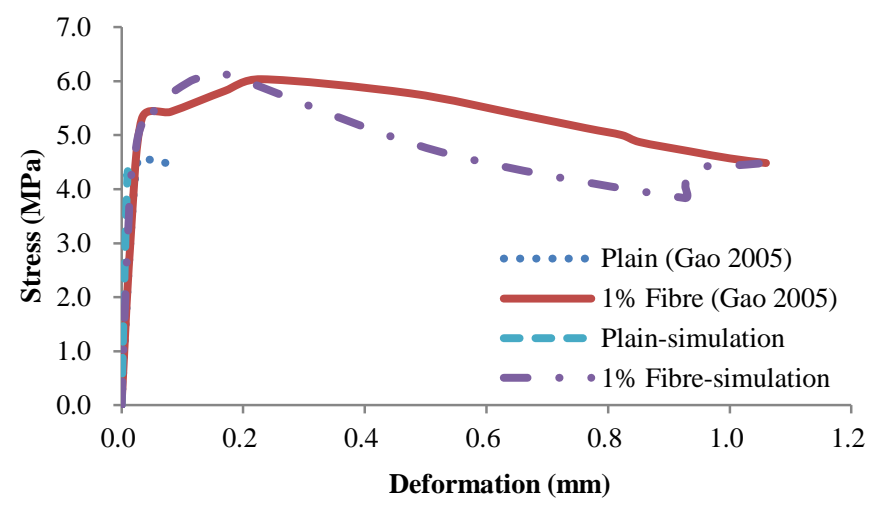


Figure 18. Split stress versus deformation

Denneman et al. [34] stated conventional experiment approaches apply Timoshenko and Goodier equations to the calculation of tensile strength and therefore assumed fracture mode could be rupture that begins from the centre of the specimen and then extends in the direction to the loading surfaces. The current simulation agrees well with this assumption. Figure 19Figure 19 shows damage development along the loading axis where fringed levels represent scaled damage measure designed for the $\mathrm{K} \& \mathrm{C}$ model in LS-DYNA. Scaled damage measure ranging from 0 to 1 means the material transitions from the yield failure surface to the maximum failure surface, and from 1 to 2 indicates the material moves from the maximum failure surface to the residual failure surface. It can be clearly seen damage starts from the centre of the model and then propagates vertically towards the top and bottom surfaces where the load is imposed. Eventually, rupture happens in the middle of the loading axis followed by crush around the loading strips. A comparison of damage modes between the current simulation and the test conducted by Gao et al. [33] is displayed in Figure 20Figure 20. The test result also shows a rupture in the middle of the loading axis of the specimen and a crush on its top. 


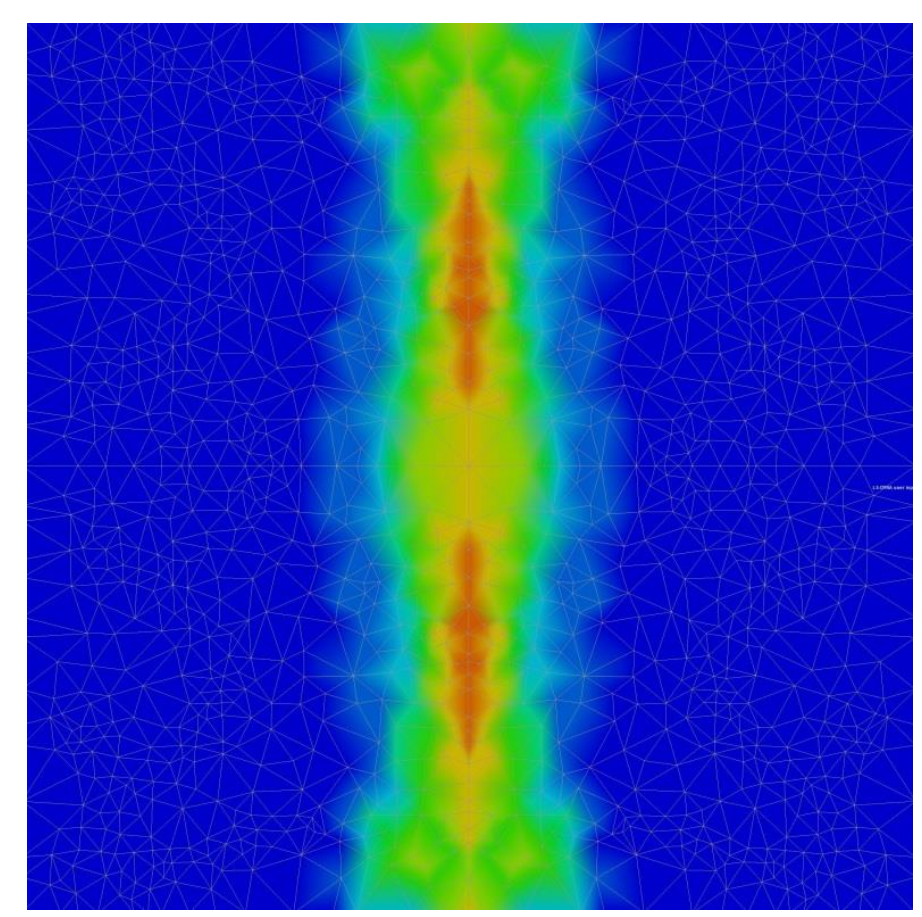

(a) Step $24 / 100$

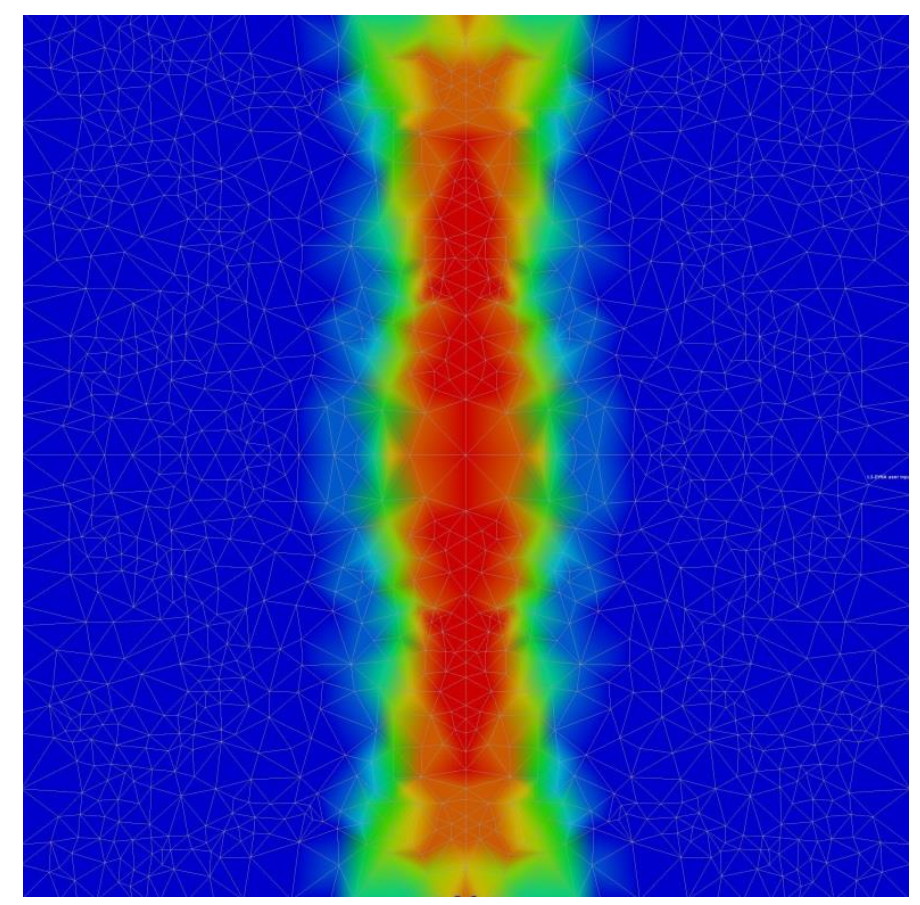

(b) Step 30/100 


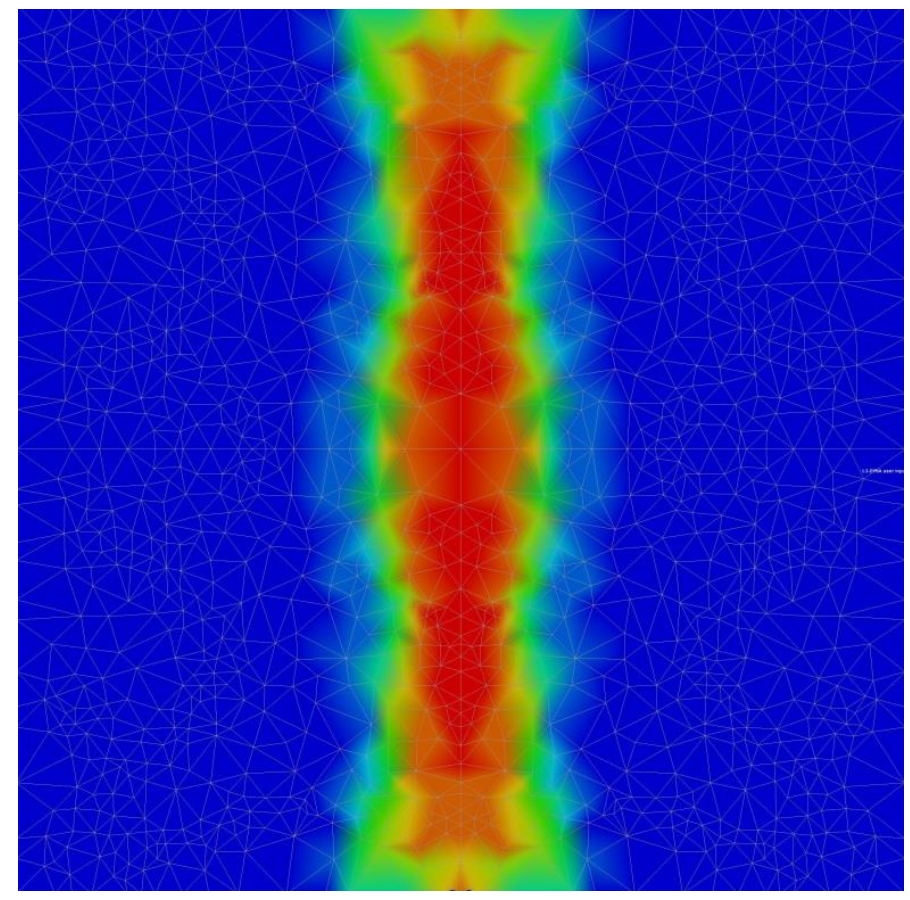

(c) Step 51/100

Figure 19. Damage development along loading axis

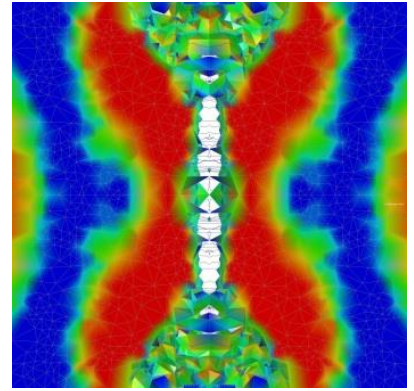

(a) Simulation

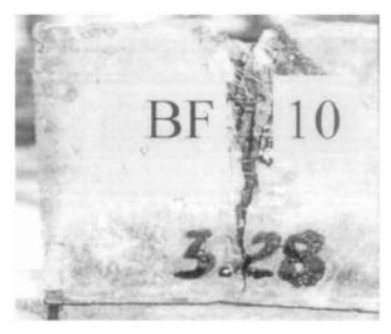

(b) test [33]

Figure 20. Comparison of damage mode between simulation and test

\section{Effect of steel fibre on properties of SFRCs}

In this section, how steel fibres including fibre content and aspect ratio affect properties of SFRCs will be investigated based on the validated 3D models. Fibre contents are divided into four groups: $0,0.5 \%, 1 \%$ and $2 \%$ and fibres have a diameter of $0.9 \mathrm{~mm}$ and a length of 40 $\mathrm{mm}$, while studies on fibre aspect ratio consist of four different fibre lengths: 30, 40, 50 and 
$60 \mathrm{~mm}$ with all fibres having an identical diameter of $0.9 \mathrm{~mm}$ (i.e. aspect ratio of 33.3, 44.4, 55.6, and 66.7).--

\subsection{Study on effect of fibre content on properties of SFRCS}

As shown in Figure 21Figure 21, four $100 \mathrm{~mm}$ cubic models with various fibre contents, i.e. 0 , $0.5 \%, 1 \%$ and $2 \%$ are numerically studied to investigate the relationship between fibre contents and SFRC properties such as compressive strength and splitting tensile strength. All fibres have a diameter of $0.9 \mathrm{~mm}$ and length of $40 \mathrm{~mm}$, and other parameters of fibre are listed in Table

\section{Table 1.}

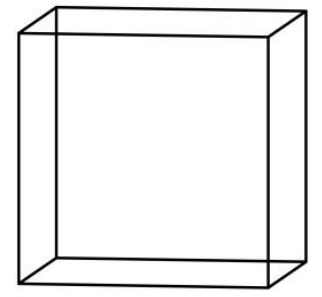

(a) Plain

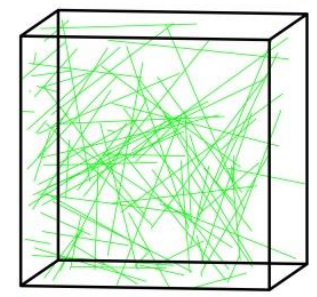

(c) $1 \%$ steel fibre

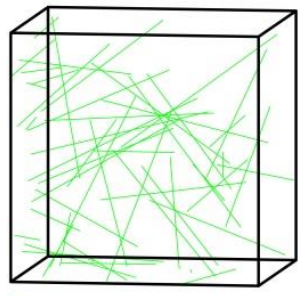

(b) $0.5 \%$ steel fibre

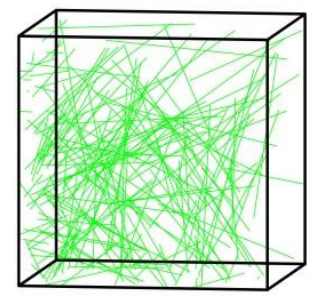

(d) $2 \%$ steel fibre

Figure 21. Geometric models with different fibre contents

\subsubsection{Compressive strength}

In this subsection, high strength concrete has the ingredients as reported in Table 2Table 2 and parameters of bond-slip contact are listed in Table 3Table 3. Under different fibre contents, 
curves of compressive strength versus strain are plotted in Figure 22Figure 22 and the relationship between compressive strength and fibre content is displayed in Figure 23Figure 23. As expected, compressive strengths of the model with steel fibres are much higher than the plain model, and the larger fibre contents the higher peak strength and peak strain. That also means toughness of models improves greatly with the increase of the addition of steel fibres. For models with various fibre contents, peak compressive stress and peak strain are listed in Table 6Table 6.

Table 6

Peak compressive stress and peak strain under various fibre contents

\begin{tabular}{lllll}
\hline & \multicolumn{4}{l}{ Fibre content (by volume) } \\
\cline { 2 - 5 } & Plain & $0.5 \%$ & $1 \%$ & $2 \%$ \\
\hline Peak strength $(\mathrm{MPa})$ & 105.7 & 138.8 & 142.6 & 150.8 \\
Peak strain $\left(10^{-3}\right)$ & 5.4 & 6.6 & 8.4 & 11.2 \\
\hline
\end{tabular}

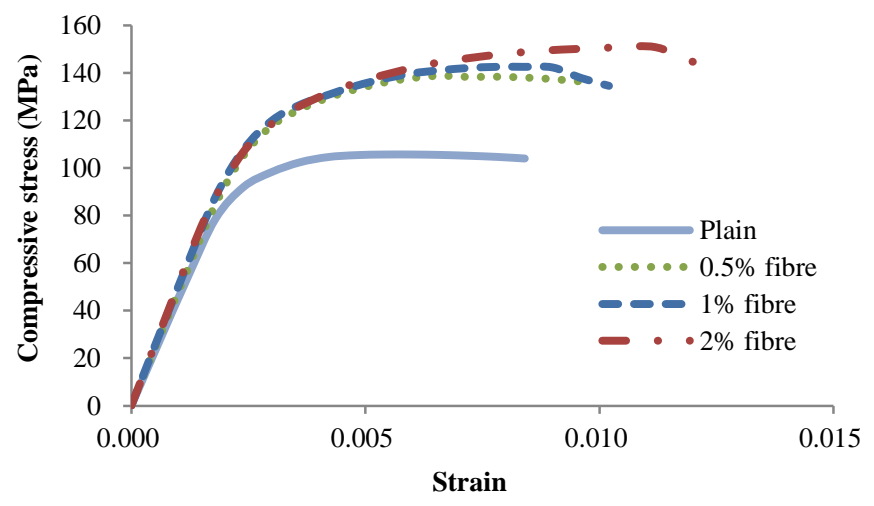

Figure 22. Compressive strength versus strain under different fibre contents 


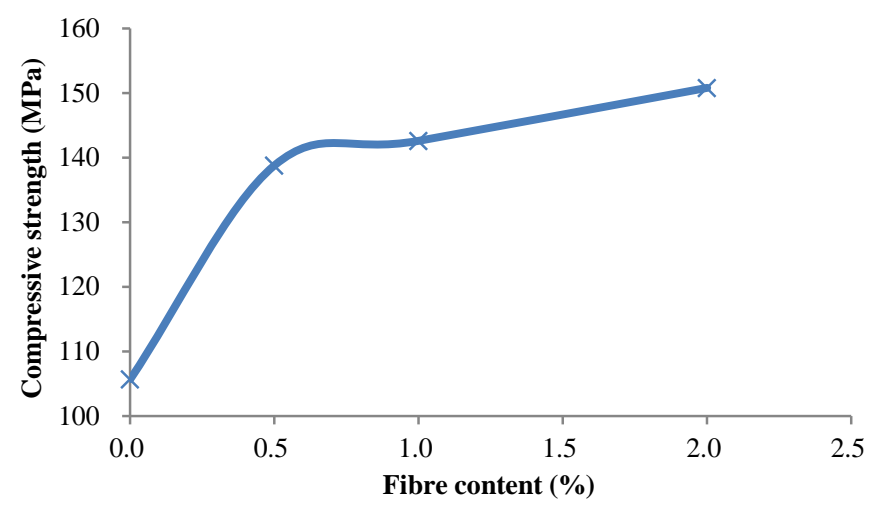

Figure 23. Relationship between compressive strength and fibre content

\subsubsection{Splitting tensile strength}

In this subsection, concrete has a compressive strength of $60 \mathrm{MPa}$. Contact properties between concrete and fibre, properties of loading steel and plywood are the same as in subsection 3.5. Similar to compression strength, with the increase of steel fibre content both peak split stress and peak deformation improve as displayed in Figure 24Figure 24. The model with $2 \%$ steel fibre by volume has a much higher peak split stress and peak deformation than the other three models, indicating splitting tensile toughness of SFRCs could be dramatically enhanced by adding enough steel fibres. Figure 25Figure 25 plots relationship between splitting tensile strength and fibre content, and Table 7 Table 7 lists the peak split stress and peak deformation under various fibre contents.

Table 7

Peak split stress and peak deformation under various fibre contents

\begin{tabular}{lllll}
\hline & \multicolumn{4}{l}{ Fibre content (by volume) } \\
\cline { 2 - 5 } & Plain & $0.5 \%$ & $1 \%$ & $2 \%$ \\
\hline Peak stress (MPa) & 5.1 & 7.3 & 7.5 & 8.7 \\
Peak deformation (mm) & 0.024 & 0.171 & 0.167 & 0.821 \\
\hline
\end{tabular}




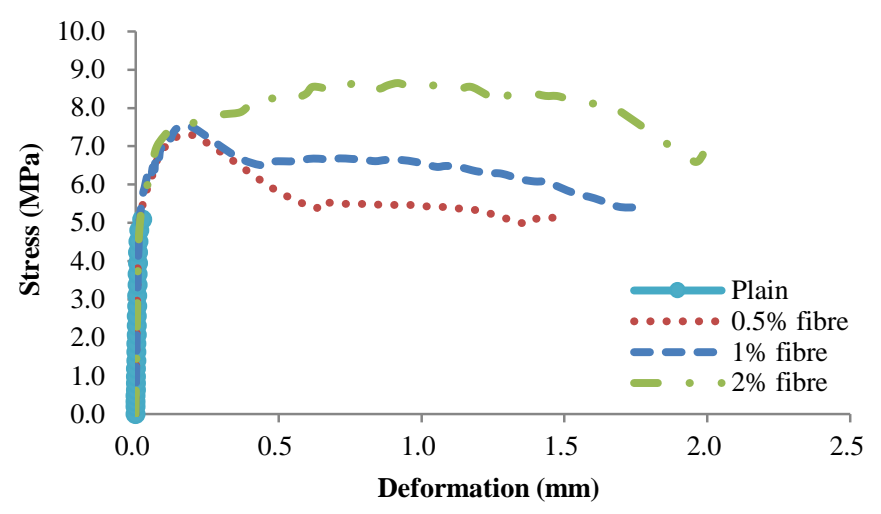

Figure 24. Split stress versus deformation under different fibre contents

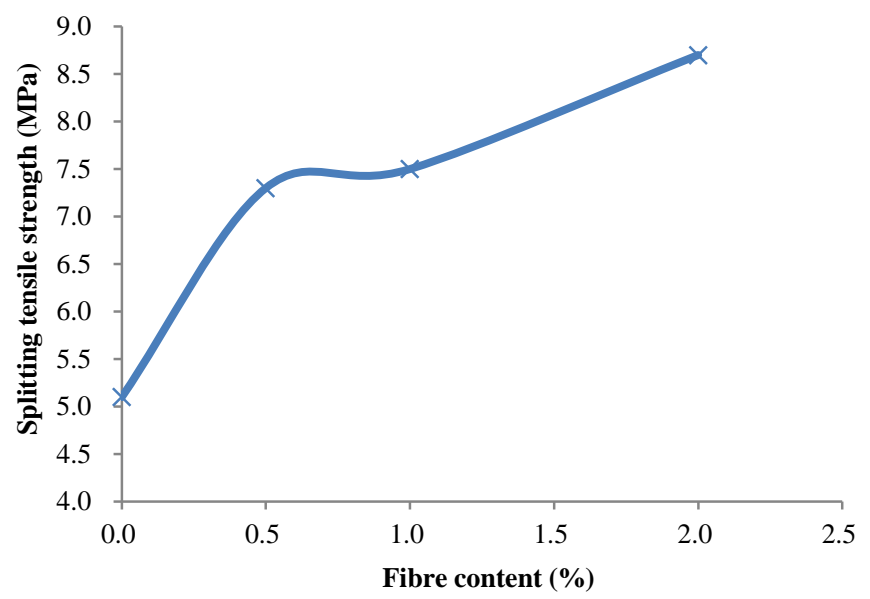

Figure 25. Relationship between splitting tensile strength and fibre content

\subsection{Study on effect of fibre length (aspect ratio) on properties of SFRCs}

Four $150 \mathrm{~mm}$ cubic models with fibre content $1 \%$ by volume but different fibre lengths, i.e. 30 , 40, 50 and $60 \mathrm{~mm}$, are simulated in this subsection. All fibres have a diameter of $0.9 \mathrm{~mm}$, and other parameters of fibre are listed in Table 1Table 1.

\subsubsection{Compressive strength}

In this subsection, high strength concrete has the ingredients as reported in Table 2Table 2 and parameters of bond-slip contact are listed in Table 3Table 3. With a diameter of $0.9 \mathrm{~mm}$, fibres 
in length of $30,40,50,60 \mathrm{~mm}$ have an aspect ratio of $33.3,44.4,55.6,66.7$, respectively. Figure 26Figure 26 shows curves of compressive strength versus strain for these four models reinforced with fibres with different lengths, and Figure 27Figure 27 depicts the relationship between compressive strength and fibre aspect ratio. Table 8 Table 8 lists peak compressive strength and peak strain for the four cases. It can be seen with the increase of fibre length or aspect ratio, compressive strength increases slightly from 132.6 to $138.2 \mathrm{MPa}$, while there is no such trend for peak strain. A similar trend was also found by Su et al. [35].

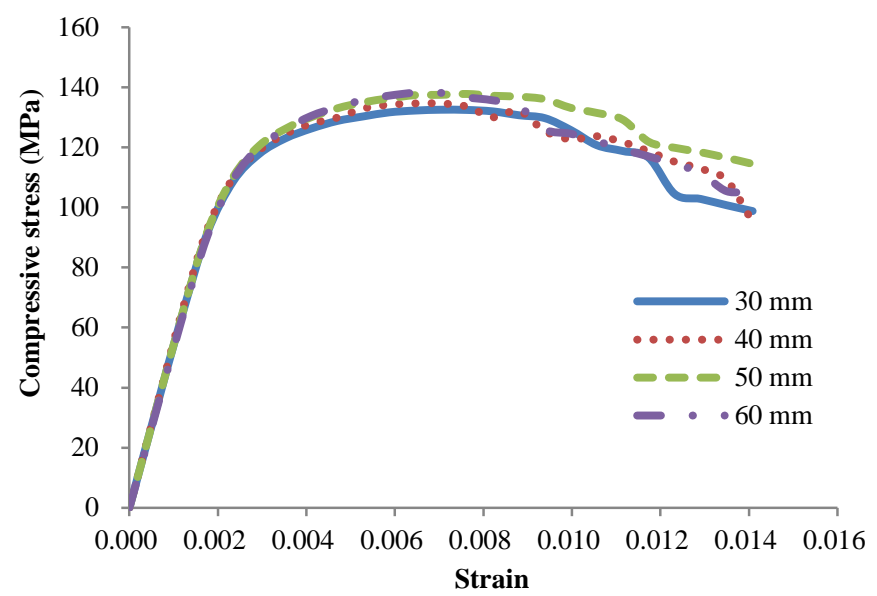

Figure 26. Compressive strength versus strain under different fibre lengths

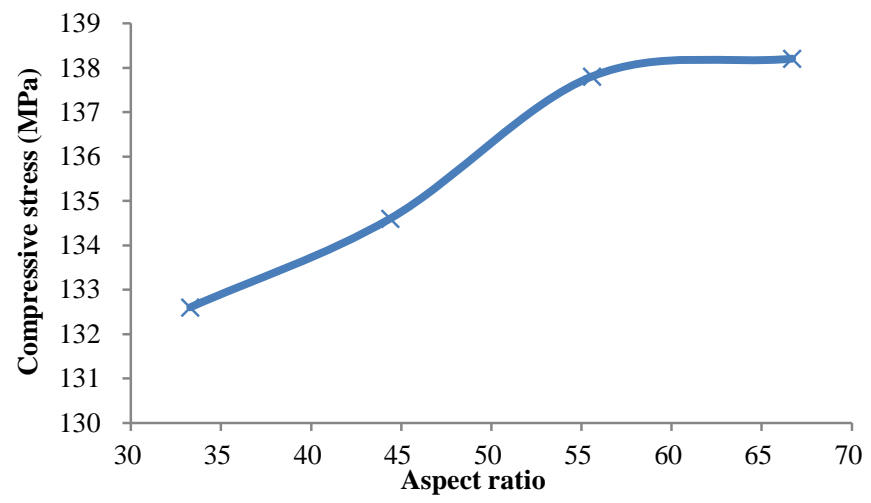

Figure 27. Relationship between compressive strength and fibre aspect ratio

Table 8

Peak compressive strength and peak strain under various fibre lengths 


\begin{tabular}{lllll}
\hline & \multicolumn{4}{l}{ Fibre length $(\mathrm{mm}) /$ Aspect ratio } \\
\cline { 2 - 5 } & $30 / 33.3$ & $40 / 44.4$ & $50 / 55.6$ & $60 / 66.7$ \\
\hline Peak strength (MPa) & 132.6 & 134.6 & 137.8 & 138.2 \\
Peak strain $\left(10^{-3}\right)$ & 7.0 & 6.5 & 7.6 & 6.5 \\
\hline
\end{tabular}

\subsubsection{Splitting tensile strength}

In this subsection, concrete has a compressive strength of $60 \mathrm{MPa}$. Contact properties between concrete and fibre, properties of loading steel and plywood are the same as in subsection 3.5. Curves of split stress versus deformation under different fibre lengths are shown in Figure 28Figure 28 and the relationship between splitting tensile strength and fibre aspect ratio is shown in Figure 29Figure 29. As can be seen with fibre length varying from $30 \mathrm{~mm}$ to $60 \mathrm{~mm}$ (or aspect ratio from 33.3 to 66.7), splitting tensile strength has a slight improvement from 5.94 $\mathrm{MPa}$ to $6.32 \mathrm{MPa}$. However, the difference of softening branches between them is much more notable as displayed in Figure 28Figure 28. Models with longer (or larger aspect ratio) fibres have higher splitting tensile toughness.

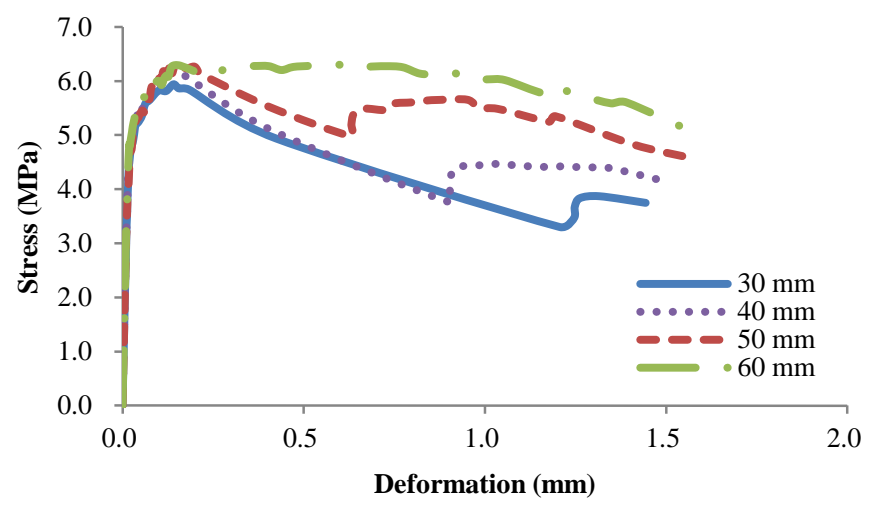

Figure 28. Split stress versus deformation under different fibre lengths 


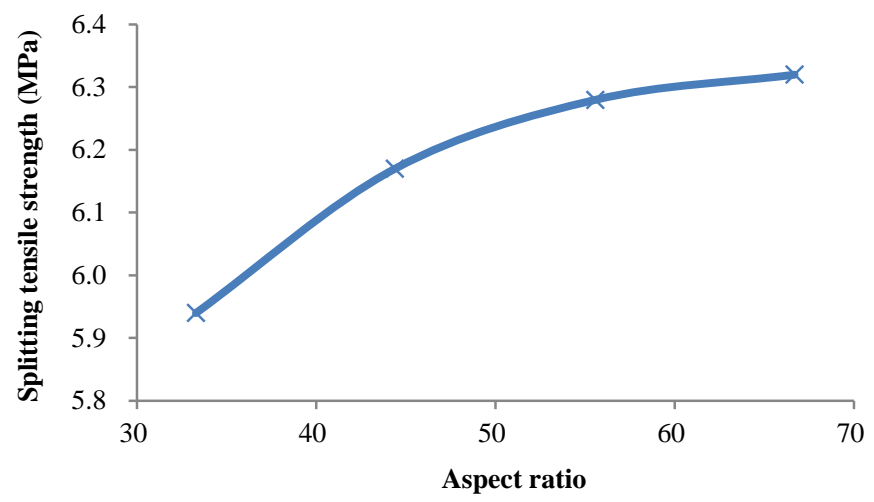

Figure 29. Relationship between splitting tensile strength and fibre aspect ratio

\section{Conclusions}

In this study, a 3D meso-scale model is proposed. Simulations of uniaxial compression, flexural tension and splitting tension are conducted so that the model is successfully verified. Then, parameter study is carried out on effect of steel fibre on properties of SFRCs. The following conclusions can be drawn:

(1) Delaunay triangulation proves to be an effective tool for unstructured mesh of SFRC models. In other words, it enables randomly distributed fibres to have an appropriate link with concrete matrix.

(2) The Delaunay triangulation program is designed so as to deal with situations where fibre endpoints are right on the model surface. An advantage of this is the developed model can simulate specimens cut from an SFRC block, which contributes to better accuracy and efficiency.

(3) Slide line contact has the capability to truly reflect the interfacial behaviour of fibre and mortar, which is explicitly modelled in this work.

(4) It is found that both fibre content and fibre aspect ratio have a positive effect on the compressive strength and splitting tensile strength of SFRCs. 


\section{Acknowledgement}

The authors gratefully acknowledge the financial support of the Australian Research Council (Grant DP160104661) and the Australian Government Research Training Program Scholarship.

\section{References}

[1] A. Caggiano, G. Etse, E. Martinelli, Zero-thickness interface model formulation for failure behavior of fiber-reinforced cementitious composites, Computers \& Structures 98-99 (2012) 23-32.

[2] U. Nyström, K. Gylltoft, Comparative numerical studies of projectile impacts on plain and steel-fibre reinforced concrete, International Journal of Impact Engineering 38(2-3) (2011) 95-105.

[3] G.H. Mahmud, Z. Yang, A.M.T. Hassan, Experimental and numerical studies of size effects of Ultra High Performance Steel Fibre Reinforced Concrete (UHPFRC) beams, Construction and Building Materials 48 (2013) 1027-1034.

[4] M. Xu, K. Wille, Calibration of K\&C Concrete Model for UHPC in LS-DYNA, Advanced Materials Research 1081 (2014) 254-259.

[5] M.J. Shannag, R. Brincker, W. Hansen, Pullout behavior of steel fibers from cement-based composites, Cement and Concrete Research 27(6) (1997) 925-936.

[6] T. Soetens, A. Van Gysel, S. Matthys, L. Taerwe, A semi-analytical model to predict the pull-out behaviour of inclined hooked-end steel fibres, Construction and Building Materials 43 (2013) 253-265.

[7] M. Tuyan, H. Yazıc1, Pull-out behavior of single steel fiber from SIFCON matrix, Construction and Building Materials 35 (2012) 571-577.

[8] Y. Shi, Z.-X. Li, H. Hao, Bond slip modelling and its effect on numerical analysis of blast-induced responses of RC columns, Structural Engineering and Mechanics 32(2) (2009) 251-267.

[9] N. Ganesan, P.V. Indira, M.V. Sabeena, Bond stress slip response of bars embedded in hybrid fibre reinforced high performance concrete, Construction and Building Materials 50 (2014) 108-115.

[10] F. Aslani, S. Nejadi, Bond characteristics of steel fibre reinforced self-compacting concrete, Canadian Journal of Civil Engineering 39(7) (2012) 834-848.

[11] S. Marfia, E. Sacco, Numerical techniques for the analysis of crack propagation in cohesive materials, International Journal for Numerical Methods in Engineering 57(11) (2003) 1577-1602.

[12] J. Oliver, D.F. Mora, A.E. Huespe, R. Weyler, A micromorphic model for steel fiber reinforced concrete, Int J Solids Struct 49(21) (2012) 2990-3007.

[13] Z. Xu, H. Hao, H.N. Li, Mesoscale modelling of fibre reinforced concrete material under compressive impact loading, Construction and Building Materials 26(1) (2012) 274-288.

[14] E. Gal, R. Kryvoruk, Meso-scale analysis of FRC using a two-step homogenization 
approach, Computers \& Structures 89(11-12) (2011) 921-929.

[15] E.-H. Yang, S. Wang, Y. Yang, V.C. Li, Fiber-bridging constitutive law of engineered cementitious composites, Journal of Advanced Concrete Technology 6(1) (2008) 181-193.

[16] E.A. Schauffert, G. Cusatis, Lattice discrete particle model for fiber-reinforced concrete. I: Theory, Journal Of Engineering Mechanics 138(7) (2012) 826-833.

[17] Z.P. Bažant, F.C. Caner, Microplane model M5 with kinematic and static constraints for concrete fracture and anelasticity. I: Theory, Journal of Engineering Mechanics 131(1) (2005) 31-40.

[18] Z.P. Bažant, F.C. Caner, Microplane Model M5 with Kinematic and Static Constraints for Concrete Fracture and Anelasticity. II: Computation, JOURNAL OF ENGINEERING MECHANICS 131(1) (2005) 41-47.

[19] J.E. Bolander, S. Choi, S.R. Duddukuri, Fracture of fiber-reinforced cement composites: effects of fiber dispersion, International Journal of Fracture 154(1-2) (2008) 73-86.

[20] V.M.C.F. Cunha, J.A.O. Barros, J.M. Sena-Cruz, A finite element model with discrete embedded elements for fibre reinforced composites, Computers \& Structures 94-95 (2012) 22-33.

[21] Y. Su, J. Li, C. Wu, P. Wu, M. Tao, X. Li, Mesoscale study of steel fibre-reinforced ultra-high performance concrete under static and dynamic loads, Materials \& Design 116 (2017) 340-351.

[22] A. Pros, P. Diez, C. Molins, Modeling steel fiber reinforced concrete: numerical immersed boundary approach and a phenomenological mesomodel for concrete-fiber interaction, International Journal for Numerical Methods in Engineering 90(1) (2012) 65-86.

[23] Q. Fang, J. Zhang, Three-dimensional modelling of steel fiber reinforced concrete material under intense dynamic loading, Construction and Building Materials 44 (2013) $118-132$.

[24] H. Borouchaki, S.H. Lo, Fast Delaunay triangulation in three dimensions, Comput. Methods Appl. Mech. Engrg. 128 (1995) 153-167.

[25] D.F. Watson, Computing the n-dimensional Delaunay tessellation with application to Voronoi polytopes, The Computer Journal 24(2) (1981) 167-172.

[26] Q. Yang, Constrained Delaunay Triangulation Meshing Technique, Publishing House of Electronics Industry, Beijing, 2005.

[27] A. Bowyer, Computing Dirichlet tessellations, The Computer Journal 24(2) (1981) $162-166$.

[28] X. Li, Sliver-free Three Dimensional Delaunay Mesh Generation, Computer Science, University of Illinois at Urbana Champaign, Urbana Illinois, 2001.

[29] Y. Wu, J.E. Crawford, J.M. Magallanes, Performance of LS-DYNA® Concrete Constitutive Models, 12th International LS-DYNA® Users Conference.

[30] Y. Wu, J.E. Crawford, S. Lan, J.M. Magallanes, Validation Studies for Concrete Constitutive Models with Blast Test Data, 13th International LS-DYNA Users Conference.

[31] LS-DYNA, Keyword Users Manual, R7.0 ed., LSTC2013.

[32] D. Gao, J. Zhao, J. Tang, An experimental study on the behavior of fiber reinforced high-strength concrete under splitting tension (in Chinese), China Civil Engineering Journal 2005(7) (2005) 21-26.

[33] D. Gao, J. Zhao, J. Tang, Experimental study on the dimensional effect of steel fiber reinforced high-strength concrete (SFRHSC) under splitting tension (in Chinese), Journal of Building Materials 7(3) (2004) 295-298.

[34] E. Denneman, E.P. Kearsley, A.T. Visser, Splitting tensile test for fibre reinforced concrete, Materials and Structures 44(8) (2011) 1441-1449.

[35] Y. Su, J. Li, C. Wu, P. Wu, Z.-X. Li, Effects of steel fibres on dynamic strength of UHPC, Construction and Building Materials 114 (2016) 708-718. 